\title{
Cancer risk in patients with Hashimoto's thyroiditis: a nationwide cohort study
}

\author{
Y-K Chen ${ }^{1,2}$, C-L Lin ${ }^{3}$, FT-F Cheng ${ }^{4,5}$, F-C Sung ${ }^{3,6}$ and C-H Kao*,7,8 \\ ${ }^{1}$ Department of Nuclear Medicine and PET Center, Taipei, Taiwan; ${ }^{2}$ School of Medicine, Fu Jen Catholic University, New Taipei \\ City, Taiwan; ${ }^{3}$ Management Office for Health Data, Taichung, Taiwan; ${ }^{4}$ Department of Surgery, Shin Kong Wu Ho-Su Memorial \\ Hospital, Taipei, Taiwan; ${ }^{5}$ National Defense Medical Center, Taipei, Taiwan; ${ }^{6}$ Department of Public Health, Taichung, Taiwan; \\ ${ }^{7}$ Department of Nuclear Medicine and PET Center, China Medical University Hospital, Taichung, Taiwan and ${ }^{8}$ Graduate Institute \\ of Clinical Medicine Science and School of Medicine, College of Medicine, China Medical University, Taichung, Taiwan
}

Background: This study examined the risk of cancer in patients with Hashimoto's thyroiditis (HT).

Methods: The Taiwanese National Health Insurance Research Database (NHIRD) was used to identify 1521 newly diagnosed HT patients from 1998-2010, and 6084 frequency-matched non-HT patients. The risk of developing cancer for HT patients was measured using the Cox proportional hazard model.

Results: The incidence of developing cancer in the HT cohort was 5.07 per 1000 person-years, which was 1.68 -fold higher than that in the comparison cohort $(P<0.001)$. Compared with patients aged 20-34 years, patients in older age groups had a higher risk of developing cancer ( $35-55$ years: hazard ratio $(H R)=5.96$; $>55$ years: $H R=9.66)$. After adjusting for sex, age, and comorbidities, the HT cohort had HRs of 4.76 and 11.8 for developing colorectal cancer and thyroid cancer, respectively, compared with non-HT cohort. Furthermore, the HT cohort to non-HT cohort incidence rate ratio (IRR) of thyroid cancer was higher in the first 3 years (48.4, 95\% confidence interval $(\mathrm{Cl})=35.0-66.3)$, with an adjusted $\mathrm{HR}$ of $49.4(95 \% \mathrm{Cl}=6.39-382.4)$.

Conclusion: Hashimoto's thyroiditis patients have a higher risk of thyroid cancer and colorectal cancer. The thyroid cancer prevention effort should start soon after HT is diagnosed, while being cautious of colorectal cancer increases with time.

Hashimoto's thyroiditis (HT) (or chronic lymphocytic thyroiditis) is an autoimmune disease that causes the immune system to attack and destroy the thyroid gland (Dayan and Daniels, 1996). The resulting inflammation often leads to an underactive thyroid gland (hypothyroidism). The disease affects between $0.1 \%$ and $5 \%$ of all adults in Western countries. It occurs more frequently in women than in men (between $10: 1$ and 20:1), and is most prevalent between 45 and 65 years of age (Kumar, 2010).

A number of studies have examined the possible association of HT with subsequent types of cancer. Hashimoto's thyroiditis has been associated with thyroid carcinoma (Dailey et al, 1955; Repplinger et al, 2008; Ahn et al, 2011). Patients with HT had an increased risk of myeloproliferative and lymphoproliferative neoplasms (Holm et al, 1985). Hashimoto's thyroiditis has also been associated with malignant lymphoma of the thyroid
(Holm et al, 1985; Hyjek and Isaacson, 1988; Motoi and Ozawa, 2005). In addition, patients with HT were at higher risk for breast cancer than those in the control group (Ito and Maruchi, 1975; Muller et al, 2011). A doubled risk of lung cancer with HT was also reported (Yamashita et al, 1979). However, a number of studies did not observe such an association with thyroid cancer (Anil et al, 2010), breast cancer (Holm et al, 1985; Maruchi et al, 1976), and lung cancer (Holm et al, 1985).

Subsequent types of cancer may be caused by the autoimmunity of TH (Holm et al, 1985). Cancer may occur because of chronic inflammation (Nose et al, 2002; Larson et al, 2007). However, the pathogenetic mechanism of the interaction between HT and cancer remains unclear. Because of the increasing incidence of HT, the health consequences of these patients are crucial (Macksood et al, 1961; Furszyfera et al, 1972). Epidemiologic data on the association 
between HT and cancer provide useful information for primary prevention and etiology research. We conducted a nationwide study to evaluate the cancer risk in Chinese patients with HT.

\section{MATERIALS AND METHODS}

Data sources. This study used claims data from the Taiwan National Health Insurance Program established by the Bureau of National Health Insurance of the Department of Health in March 1995. The insurance program provides health care to $99 \%$ of the total population (23.74 million people) and is contracted to $97 \%$ of the hospitals and clinics in Taiwan (Cheng, 2009). The National Health Research Institutes Dataset (NHRID) was established in January 1996; the data set established a random sample with a representative population of 1000000 people (approximately 5\% of the entire insured population) based on the 2000 reimbursement data for public access. The National Health Research Institute (NHRI) reported no statistically significant differences in the distribution of sex, age, or health care expenditures between the subset of the NHIRD and all enrollees. The NHRID included information on the registry of medical services, prescribed medications, inpatient orders, ambulatory care, and the registration file with scrambled identification. Available sociodemographic information on the study participants included sex, birth date, occupation, income levels, and residential area. This cohort study was approved by the Ethics Review Board of China Medical University (CMU-REC-101-012).

Study participants. All diagnosis codes were classified according to the International Classification of Diseases, 9th Revision, Clinical Modification (ICD-9-CM). Newly diagnosed HT patients (ICD-9-CM codes 245.2) from 1998-2010 were recruited as the study cohort. The date of HT diagnosis was defined as the index date. We excluded patients with a history of malignant cancer (ICD-9-CM codes 140-208) diagnosed before the index date. The non-HT cohort consisted of randomly selected people (age, sex, and month of HT diagnosis) insured from 1998-2010 without a history of HT and/or malignant cancer. The case-to-control ratio was $1: 4$. A total of $1521 \mathrm{HT}$ cases and 6084 references were used in this study.

Criteria and definition. The confirmation of malignant cancer (ICD-9-CM code 140-195 and 200-208) events was based on the registry of Catastrophic Illness Patient Database (CIPD). Accurate codes were used for all diagnoses of cancer by doctors and officials of the National Health Insurance. Each patient was examined from the index date for the occurrence of cancer, death, withdrawal from the insurance, or until the end of 2010. Patients with baseline comorbidity, including diabetes (ICD-9-CM codes 250), hyperlipidemia (ICD-9-CM codes 272), hypertension (ICD-9-CM codes 401-405), and heart disease (HD) (ICD-9-CM codes 410-414, 425-429) were also identified.

Data analysis. Data analysis was used to compare distributions of gender, age, and comorbidity between the HT cohort and the nonHT cohort, which were tested using the $\chi^{2}$-test. The mean age between both cohorts was compared and tested using $t$-test. We calculated the sex-specific, age-specific, and comorbidity-specific incidence density rates of cancer using person-years in each cohort. The HT cohort to non-HT cohort incidence rate ratio (IRR) of cancer was estimated using Poisson regression. The Cox proportional hazard regression model was used to assess the risk of developing cancer associated with HT. The hazard ratios (HRs) and $95 \%$ confidence intervals (CIs) were estimated using the Cox model, which controlled for sociodemographic factors. The Kaplan-Meier method was used to compare the probability of cancer-free events and survival between both cohorts and the log-rank test was used to examine the differences. All statistical analyses were performed using SAS 9.2 (SAS Institute, Cary, NC, USA), and the Kaplan-Meier survival curve was plotted using $\mathrm{R}$ software ( $\mathrm{R}$ Foundation for Statistical Computing, Vienna, Austria). All statistical tests were performed at the two-tailed significance level of 0.05 .

\section{RESULTS}

Table 1 shows the basal characteristic results. Most patients were female $(90.0 \%)$ and $\leqslant 55$ years of age $(84.1 \%)$. Patients in the study cohort were more likely to have diabetes $(9.66 \%$ vs $6.79 \%)$, hypertension (15.5\% vs 14.2\%), hyperlipidemia (15.7\% vs $10.7 \%$ ), and heart disease (17.6\% vs $10.9 \%)$.

Compared with the non-HT cohort, participants with HT were 1.68 times more likely to develop cancer (a rate of $5.07 v s 3.03$ per 1000 person-years), with adjusted HRs of 1.68 (95\% CIs $=1.18-2.38)$ (Table 2). In both cohorts, men had a greater incidence rate of HT than women; however, women had a greater IRR than men $(\mathrm{IRR}=1.79, \quad 95 \% \quad \mathrm{CIs}=1.52-2.10 \quad$ vs $\quad \mathrm{IRR}=1.14 \quad$ with $95 \%$ CIs $=0.69-1.89)$. The adjusted HRs were significantly higher in men than women $(\mathrm{HRs}=1.67,95 \% \mathrm{CIs}=1.06-2.60)$. The agespecific incidence rate of cancer shows that the incidence rate increased with age in both cohorts, and the IRR of cancer was highest in the group aged $\leqslant 35$ years (IRR $=3.95,95 \%$ CIs $=3.09-5.04$ ). However, the adjusted HRs were 9.66 (95\% CIs $=5.15-18.1)$ for the older group ( $>55$ years) compared with participants of $\leqslant 35$ years of age. The comorbidity-specific analysis showed that the incidence rate of cancer was consistently higher with these comorbidities in both cohorts.

Table 3 shows the specific analyses on sub division cancer between the HT and non-HT cohorts. Compared with the non-HT cohort, the adjusted HRs of developing colorectal cancer and thyroid cancer were 4.76-fold and 11.8-fold higher for patients with HT (95\% CI = 1.36-16.6 and 4.24-33.1, respectively), which was statistically significant.

\begin{tabular}{|c|c|c|c|}
\hline & \multicolumn{2}{|c|}{ Hashimoto's thyroiditis } & \multirow[b]{2}{*}{$\boldsymbol{P}$-value } \\
\hline & $\begin{array}{c}\text { No } \\
(\mathbf{N}=6084)\end{array}$ & $\begin{array}{c}\text { Yes } \\
(\mathbf{N}=1521)\end{array}$ & \\
\hline \multicolumn{4}{|l|}{ Gender } \\
\hline $\begin{array}{l}\text { Women } \\
\text { Men }\end{array}$ & $\begin{array}{r}5476(90.0) \\
603(10.0) \\
\end{array}$ & $\begin{array}{r}1369(90.0) \\
152(10.0) \\
\end{array}$ & 0.99 \\
\hline \multicolumn{4}{|l|}{ Age stratified } \\
\hline $\begin{array}{l}\leqslant 35 \\
35-55 \\
55+ \\
\text { Age, mean (s.d.) }\end{array}$ & $\begin{array}{r}2500(41.1) \\
2616(43.0) \\
968(15.9) \\
39.8(15.2)\end{array}$ & $\begin{array}{l}625(41.1) \\
645(43.0) \\
242(15.9) \\
39.9(15.2)\end{array}$ & $0.94^{\mathrm{a}}$ \\
\hline \multicolumn{4}{|l|}{ Comorbidity } \\
\hline $\begin{array}{l}\text { Diabetes } \\
\text { Hypertension } \\
\text { Hyperlipidemia } \\
\text { Heart disease }\end{array}$ & $\begin{array}{l}413(6.79) \\
864(14.2) \\
648(10.7) \\
663(10.9)\end{array}$ & $\begin{array}{l}147(9.66) \\
236(15.5) \\
238(15.7) \\
268(17.6)\end{array}$ & $\begin{aligned} & 0.0001 \\
& 0.19 \\
< & 0.0001 \\
< & 0.0001\end{aligned}$ \\
\hline $\begin{array}{l}\chi^{2} \text {-test. } \\
{ }_{\text {a }} \text { T-test. }\end{array}$ & & & \\
\hline
\end{tabular}


Table 2. Comparison of incidence densities of cancer and hazard ratio between with and without Hashimoto's thyroiditis by demographic characteristics

Hashimoto's thyroiditis

\begin{tabular}{|c|c|c|c|c|c|c|c|c|}
\hline & \multicolumn{3}{|c|}{ No } & \multicolumn{3}{|c|}{ Yes } & \multirow[b]{2}{*}{$\mathrm{IRR}^{\mathrm{b}}(95 \% \mathrm{Cl})$} & \multirow[b]{2}{*}{ Adjusted $\mathrm{HR}^{\mathrm{c}}(95 \% \mathrm{Cl})$} \\
\hline & Event & PY & Rate $^{a}$ & Event & PY & Rate $^{a}$ & & \\
\hline All cancer & 108 & 35692 & 3.03 & 45 & 8870 & 5.07 & $1.68(1.44,1.96)^{\star \star \star}$ & $1.68(1.18,2.38)^{\star \star \star}$ \\
\hline \multicolumn{9}{|l|}{ Sex } \\
\hline $\begin{array}{l}\text { Female } \\
\text { Male }\end{array}$ & $\begin{array}{l}90 \\
18\end{array}$ & $\begin{array}{r}32529 \\
3163\end{array}$ & $\begin{array}{l}2.77 \\
5.69\end{array}$ & $\begin{array}{r}40 \\
5\end{array}$ & $\begin{array}{r}8099 \\
771\end{array}$ & $\begin{array}{l}4.94 \\
6.49\end{array}$ & $\begin{array}{l}1.79(1.52,2.10)^{\star \star \star} \\
1.14(0.69,1.89)\end{array}$ & $\begin{array}{r}1 \text { (Reference) } \\
1.67(1.06,2.60)\end{array}$ \\
\hline \multicolumn{9}{|l|}{ Age } \\
\hline $\begin{array}{l}\leqslant 35 \\
35-55 \\
55+\end{array}$ & $\begin{array}{r}8 \\
65 \\
35\end{array}$ & $\begin{array}{r}16199 \\
14982 \\
4512\end{array}$ & $\begin{array}{l}0.49 \\
4.34 \\
7.76\end{array}$ & $\begin{array}{r}8 \\
24 \\
13\end{array}$ & $\begin{array}{l}4104 \\
3671 \\
1096\end{array}$ & $\begin{array}{r}1.95 \\
6.54 \\
11.86\end{array}$ & $\begin{array}{l}3.95(3.09,5.04)^{\star \star \star} \\
1.51(1.20,1.89)^{\star \star \star} \\
1.53(1.06,2.21)^{\star}\end{array}$ & $\begin{array}{c}1 \text { (Reference) } \\
5.96(3.49,10.2)^{\star \star \star} \\
9.66(5.15,18.1)^{\star \star \star}\end{array}$ \\
\hline
\end{tabular}

\section{Comorbidity}

\section{Diabetes}

\begin{tabular}{|l|l|r|r|r|r|r|r|r|}
\hline No & 93 & 33590 & 2.77 & 38 & 8076 & 4.71 & $1.70(1.44,2.00)^{\star \star \star *}$ & 1 (Reference) \\
Yes & 15 & 2102 & 7.14 & 7 & 794 & 8.82 & $1.24(0.75,2.03)$ & $1.22(0.73,2.03)$ \\
\hline
\end{tabular}

Hypertension

\begin{tabular}{|l|l|l|l|l|l|l|l|r|r}
\hline No & 78 & 31253 & 2.50 & 35 & 7695 & 4.55 & $1.82(1.54,2.15)^{\star * *}$ & 1 (Reference) \\
Yes & 30 & 4439 & 6.76 & 10 & 1175 & 8.51 & $1.26(0.84,1.88)$ & $1.06(0.68,1.65)$ \\
\hline
\end{tabular}

\section{Hyperlipidemia}

\begin{tabular}{l|l|r|r|r|l|l|l|r|} 
No & 88 & 32417 & 2.71 & 37 & 7645 & 4.84 & $1.78(1.51,2.10)^{\star \star \star}$ & 1 (Reference) \\
Yes & 20 & 3276 & 6.11 & 8 & 1225 & 6.53 & $1.07(0.70,1.64)$ & $0.85(0.52,1.37)$
\end{tabular}

\section{Heart disease}

\begin{tabular}{|l|l|l|l|l|l|l|l|r|r|r}
\hline No & 85 & 32370 & 2.63 & 34 & 7509 & 4.53 & $1.72(1.46,2.04)^{\star \star \star}$ & 1 (Reference) \\
Yes & 23 & 3322 & 6.92 & 11 & 1361 & 8.08 & $1.17(0.79,1.73)$ \\
\hline
\end{tabular}

Abbreviation: $\mathrm{PY}=$ person-years.

${ }^{\star} P<0.05,{ }^{* \star *} P<0.001$.

${ }^{a}$ Rate, incidence rate, per 1000 person-years.

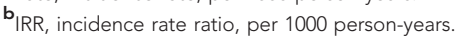

${ }^{c}$ Adjusted HR: multivariable analysis including sex, age, and comorbidities of diabetes, hypertension, hyperlipidemia, heart disease.

Figures 1A and B show that the HT cohort had a significantly higher cumulative proportion of colorectal cancer $(P=0.02)$ (Figure $1 \mathrm{~A})$ and thyroid cancer $(P<0.0001)$ compared with the non-HT cohort.

Within 3 years after HT diagnosis, the incidence rate of thyroid cancer was higher in the HT cohort than the non-HT cohort (30.6 vs 0.63 per 1000 person-years) (Table 4). Specifically, the HT cohort had a 49.4-fold risk of developing thyroid cancer in the first 3 years compared with the non-HT cohort $(95 \% \mathrm{CI}=6.39-382.4)$. The incidence rate of colorectal cancer was higher in the HT cohort than the non-HT cohort (8.09 vs 1.51 per 1000 person-years) after 3 years. The HT cohort had a 5.61-fold risk of developing colorectal cancer after 3 years compared with the non-HT cohort $(95 \% \mathrm{CI}=1.26-25.1)$.

\section{DISCUSSION}

This study used a comprehensive national database to investigate the incidence of cancer in a group of 1521 HT patients. A 1-to-4 comparison was conducted for 6084 controls, which were randomly frequency-matched for age, sex, and index year, with adjustments for baseline comorbidities that may cause a predisposition to cancer, including diabetes mellitus, hypertension, hyperlipidemia, and heart disease. Hashimoto's thyroiditis patients were more likely to be diagnosed with thyroid and colorectal cancer, with an aHR of 11.8 and 4.76, respectively. Knowing the cancer risk is valuable in the prevention and care of HT patients. In addition, this study showed that older subjects in the HT cohort had a higher risk of developing cancer compared with the younger ones. It is important to note that the aHR of thyroid cancer is much higher in HT patents in the early 3 years of follow-up, while higher colorectal cancer risk appears later. The increased thyroid cancer risk appears in early years since HT have been diagnosed may be due to the coincident findings of thyroid cancer with HT. This reflects the result of early thyroid cancer diagnosis from hard investigation when diagnosis and treatment for HT are undergoing.

Patients with HT had a statistically significant higher incidence density ratio of colorectal, breast, uterus, prostate, kidney, thyroid, and haematologic cancer compared with the comparison cohort $(\mathrm{IRR}=4.02,1.78,2.01,2.01,2.68,11.3$, and 8.05, respectively). The incidence density ratio of thyroid lymphoma (1.01) was not statistically significant. Some report revealed the malignancy most strongly associated with HT (Holm et al, 1985; Hyjek and Isaacson, 1988; 
Table 3. Site-specific incidence rate ratio and hazard ratios of cancer between with and without Hashimoto's thyroiditis

Hashimoto's thyroiditis

\begin{tabular}{|c|c|c|c|c|c|c|}
\hline \multirow[b]{2}{*}{ Cancer site } & \multicolumn{2}{|c|}{ No } & \multicolumn{2}{|c|}{ Yes } & \multirow[b]{2}{*}{$\operatorname{IRR}^{\mathrm{b}}(95 \% \mathrm{Cl})$} & \multirow[b]{2}{*}{ Adjusted $\mathrm{HR}^{\mathrm{c}}(95 \% \mathrm{Cl})$} \\
\hline & Event & Rate $^{a}$ & Event & Rate $^{a}$ & & \\
\hline Head and neck & 8 & 0.22 & 1 & 0.11 & $0.50(0.38,0.67)^{\star \star \star}$ & $0.53(0.07,4.33)$ \\
\hline Stomach & 6 & 0.17 & 0 & 0.00 & - & - \\
\hline Colorectal & 5 & 0.14 & 5 & 0.56 & $4.02(3.41,4.75)^{\star \star \star}$ & $4.76(1.36,16.6)^{*}$ \\
\hline Hepatoma & 11 & 0.31 & 2 & 0.23 & $0.73(0.058,0.93)^{\star}$ & $0.68(0.15,3.08)$ \\
\hline Lung & 10 & 0.28 & 0 & 0.00 & - & - \\
\hline Breast & 34 & 0.95 & 15 & 1.69 & $1.78(1.50,2.10)^{\star \star \star}$ & $1.70(0.92,3.15)$ \\
\hline Uterus & 2 & 0.06 & 1 & 0.11 & $2.01(1.65,2.46)^{\star \star \star}$ & $2.00(0.18,22.6)$ \\
\hline Cervical & 5 & 0.14 & 0 & 0.00 & - & - \\
\hline Ovary & 1 & 0.03 & 0 & 0.00 & - & - \\
\hline Prostate & 2 & 0.06 & 1 & 0.11 & $2.01(1.65,2.45)^{\star \star \star}$ & $2.89(0.21,39.8)$ \\
\hline Bladder & 1 & 0.03 & 0 & 0.00 & - & - \\
\hline Kidney & 3 & 0.08 & 2 & 0.23 & $2.68(2.25,3.20)^{\star \star \star}$ & $2.40(0.38,15.1)$ \\
\hline Thyroid & 5 & 0.14 & 14 & 1.58 & $11.3(9.29,13.7)^{\star \star \star}$ & $11.8(4.24,33.1)^{\star \star \star}$ \\
\hline Thyroid lymphoma & 4 & 0.11 & 1 & 0.11 & $1.01(0.80,1.28)$ & $0.94(0.10,8.58)$ \\
\hline Hematologic & 1 & 0.03 & 2 & 0.23 & $8.05(6.64,9.75)^{\star \star \star}$ & $7.95(0.71,88.8)$ \\
\hline Others & 10 & 0.28 & 1 & 0.11 & $0.40(0.30,0.54)^{\star \star \star}$ & $0.45(0.06,3.57)$ \\
\hline
\end{tabular}

${ }^{\star} P<0.05,{ }^{*} * P<0.001$. ICD-9-CM: head and neck cancer, 140.0-149.9; stomach cancer, 151.0-151.9; colorectal cancer, 153.0-154.9; liver cancer, 155.0-155.9; lung cancer, 162.0-162.9; breast cancer, 174.0-175.9; uterus and corpus cancer, 179.0-179.9 and 182.0-182.9; cervical cancer, 180.0-180.9; ovary cancer, 183.0-183.9; prostate cancer, 185.0-185.9; bladder cancer, 188.0-188.9; kidney cancer, 189.0-189.9; thyroid cancer, 193.0-193.9; thyroid lymphoma, 202.01 and 202.81; hematologic, $200.0-208.9$ (but included 202.01 and 202.81).

${ }^{a}$ Rate, incidence rate, per 1000 person-years.

IIRR, incidence rate ratio, per 1000 person-years.

cAdjusted HR: multivariable analysis including sex, age, and comorbidities of diabetes, hypertension, hyperlipidemia, heart disease.

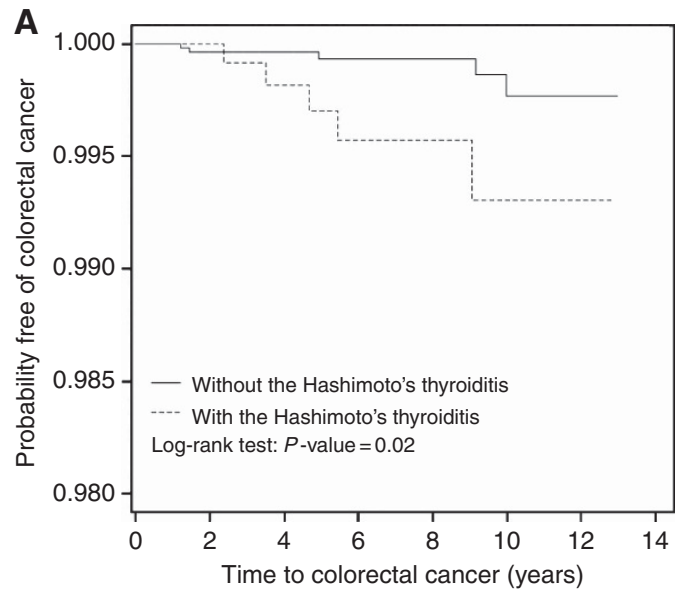

Figure 1. Probability free of colorectal cancer (A), and thyroid cancer thyroiditis.

Motoi and Ozawa, 2005). Our data show thyroid lymphoma rates are not increased, probably because it is very rare. After adjusting for sex, age, and comorbidities, the aHRs for developing thyroid and colorectal cancer had statistical significance. In addition, the aHRs of HT patients with hypothyroid (234) for developing cancer did not have statistical significance (HRs $=1.32$, $95 \%$ CIs $=0.67-2.59)$.

The coexistence of HT and thyroid carcinoma has a frequency from $<1 \%-23 \%$ (Cheng, 2009). A link between thyroid cancer

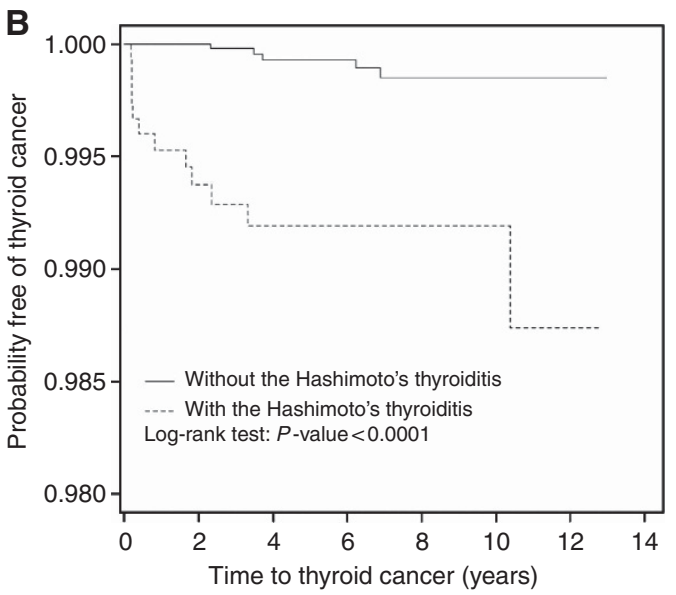

(B) for patients with (dashed line) or without (solid line) Hashimoto's

(in particular, the PTC histotype) and autoimmune thyroid diseases has long been recognized, although the precise relationship between the two diseases remains unclear. Hashimoto's thyroiditis is an autoimmune disorder in which the immune system reacts against a variety of thyroid antigens. An epidemiological association has been identified between HT and thyroid cancer (Segal et al, 1985; Ott et al, 1987; Eisenberg and Hensley, 1989; Sclafani et al, 1993; Di Pasquale et al, 2001; Pisanu et al, 2003). The relationship between inflammation and thyroid cancer 


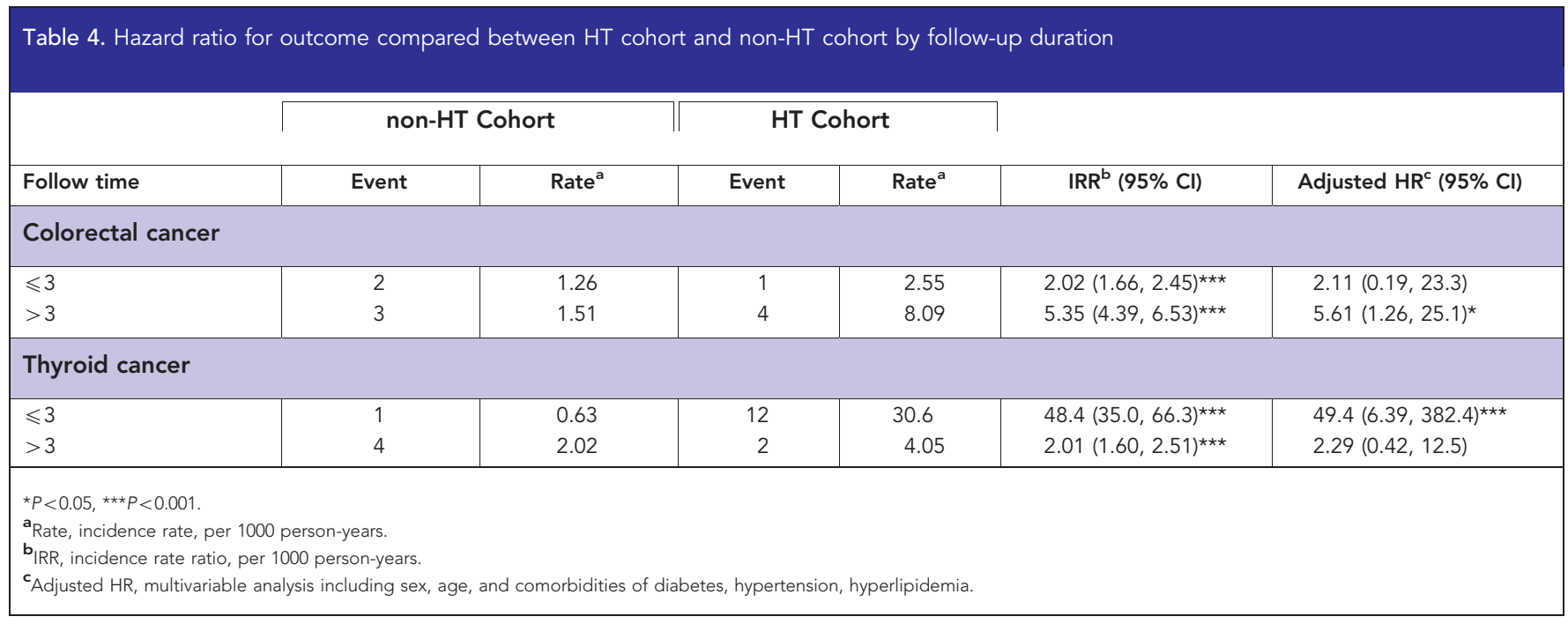

is complex and remains unclear. Epidemiological and histological data indicate that thyroid cancer frequently occurs in the context of HT, which is one of the most common autoimmune thyroid diseases, and that thyroid cancer is frequently infiltrated by inflammatory-immune cells (Guarino et al, 2010). The increased incidence of carcinomas in patients with HT suggests that thyroiditis may be a precancerous condition.

Inflammation is a physiological protective process used by organisms in response to tissue damage. Inflammation is an autolimiting process; however, abnormal persistence of the stimuli that induce the inflammatory response or failure of the mechanisms that terminate it result in chronic inflammation (Coussens and Werb, 2002). A functional relationship between chronic inflammation and cancer has been supported by clinical and epidemiological evidence. Patients with HT were three times more likely to have thyroid cancer, suggesting a strong link between chronic inflammation and cancer development (Larson et al, 2007). The most compelling evidence is the association between intestinal chronic inflammatory diseases (Crohn's disease and ulcerative rectocolitis) and adenocarcinoma of the colon (Balkwill and Mantovani, 2001; Guarino et al, 2010). A prior study showed that cyclooxygenase-2 (COX-2) expression is localized primarily in the mononuclear inflammatory cells, and was elevated in HT patients. Furthermore, follicular adenomas and papillary and follicular carcinomas exhibited strong COX-2 expression, indicating consistent upregulation in thyroid tumorigenesis, which was also observed for other organs, such as the colorectum (Eberhart et al, 1994; Sano et al, 1995). Because COX-2 expression was observed in follicular adenomas and papillary and follicular carcinomas, the enzyme may be involved in early processes of thyroid tumorigenesis, similar to cases with colorectal adenomas and carcinomas (Nose et al, 2002). The link between inflammation and cancer has been effectively established; however, the pathophysiology mechanism between HT and cancer requires further examination.

This study had a few limitations. First, we have evaluated a limited number of comorbidities for the cancer risk associations. These are most common comorbidities, but no significance associated with overall cancer appears in the data analysis. It is likely that comorbidities of less prevalence might not have significant association with the thyroid cancer and colorectal cancer as well. Second, the NHIRD does not provide detailed patient information, such as smoking habits, alcohol consumption, body mass index (BMI), physical activity, socioeconomic status, and family history of cancer. However, these covariates may have a less important role in this study because of strong relationship between HT and risk of thyroid cancer. Third, results derived from a cohort study are generally of lower methodological quality than those derived from randomized trials, because a cohort study design is subject to bias related to adjustments for confounders. Despite our meticulous study design, including adequate control of confounding factors, bias may remain because of possible unmeasured or unknown confounders. Fourth, the diagnoses recorded in NHI claims are used primarily for administrative billing; therefore, they are not subject to verification for scientific purposes. We were unable to contact the patients directly to obtain additional information because of the anonymity ensured by the identification numbers. In addition, our analyses excluded cancer patients prior to this study. This omission may have resulted in an underestimation of HT patients, and may have weakened the observed association. However, the obtained data on HT therapy and cancer diagnoses were highly reliable. Finally, we agree that the incidence of individual cancers is of low meaning because of small number of events. Hashimoto's thyroiditis is a rare disease with an incidence of approximately 1.4 per 10000 in the general population in this study. However, the important part of this study is that patients with HT are at very high risk of thyroid cancer and also at an elevated risk of colorectal cancer. The association between HT and colorectal cancer has not been established previously. Our cohort study proved previous studies of small sample sizes for thyroid cancer. In other words, this study suggests that clinicians should pay higher attention to the risk of these two cancers.

This study provides valuable information. This is the first largescale nationwide cohort study of cancer and HT conducted in an Asian population. Patients with HT, particularly older patients, are at higher risk of developing thyroid and colorectal cancer compared with the general population. In addition, HT patients have an increased relative risk of developing thyroid and colorectal cancer within 3 years and after 3 years, respectively. Clinicians managing HT patients, especially older patients, must be aware of the possible increased risk of thyroid and colorectal cancer within 3 years and after 3 years, respectively. Therefore, strategies to facilitate the prevention of thyroid and colorectal cancer are recommended for these patients.

\section{ACKNOWLEDGEMENTS}

This work was supported by the study hospital (DMR-102-014 and DMR-102-023); Taiwan Department of Health Clinical Trial and Research Center and for Excellence (DOH102-TD-B111-004), Taiwan Department of Health Cancer Research 
Center for Excellence (DOH102-TD-C-111-005); and International Research-Intensive Centers of Excellence in Taiwan (I-RiCE) (NSC101-2911-I-002-303).

\section{CONFLICT OF INTEREST}

The authors declare no conflict of interest.

\section{REFERENCES}

Ahn D, Heo SJ, Park JH, Kim JH, Sohn JH, Park JY, Park SK, Park J (2011) Clinical relationship between Hashimoto's thyroiditis and papillary thyroid cancer. Acta Oncol 50(8): 1228-1234.

Anil C, Goksel S, Gursoy A (2010) Hashimoto's thyroiditis is not associated with increased risk of thyroid cancer in patients with thyroid nodules: a single-center prospective study. Thyroid 20(6): 601-606.

Balkwill F, Mantovani A (2001) Inflammation and cancer: back to Virchow? Lancet 357(9255): 539-545.

Cheng TM (2009) Taiwan's National Health Insurance System: High value for the dollar. In Okma KGH, Crivelli L eds. Six Countries, Six Reform Models: The Health Reform Experience of Israel, The Netherlands, New Zealand, Singapore, Swit zerland and Taiwan. World Scientific: New Jersey, pp 71-204.

Coussens LM, Werb Z (2002) Inflammation and cancer. Nature 420(6917): 860-867.

Dailey ME, Lindsay S, Skahen R (1955) Relation of thyroid neoplasms to Hashimoto's disease of the thyroid gland. Arch Surg 70(2): 291-297.

Dayan CM, Daniels GH (1996) Chronic autoimmune thyroiditis. N Engl J Med 335(2): 99-107.

Di Pasquale M, Rothstein JL, Palazzo JP (2001) Pathologic features of Hashimoto's-associated papillary thyroid carcinoma. Hum Pathol 32(1): 24-30.

Eberhart CE, Coffey RJ, Radhika A, Giardiello FM, Ferrenbach S, DuBois RN (1994) Up-regulation of cyclooxygenase-2 gene expression in human colorectal adenomas and adenocarcinomas. Gastroenterology 107(4): 1183-1188.

Eisenberg BL, Hensley SD (1989) Thyroid cancer with coexistent Hashimoto's thyroiditis. Clinical assessment and management. Arch Surg 124(9): 1045-1047.

Furszyfera J, Kurlanda LT, McConaheya WM, Woolnera LB, Elveback LR (1972) Epidemiologic aspects of Hashimoto's thyroiditis and Graves' disease in Rochester, Minnesota (1935-1967), with special reference to temporal trends. Metabolism 21(3): 197-204.

Guarino V, Castellone MD, Avilla E, Melillo RM (2010) Thyroid cancer and inflammation. Mol Cell Endocrinol 321(1): 94-102.

Holm L-E, Blomgren H, Löwhagen T (1985) Cancer risks in patients with chronic lymphocytic thyroiditis. N Engl J Med 312(10): 601-604.
Hyjek E, Isaacson PG (1988) Primary B cell lymphoma of the thyroid and its relationship to Hashimoto's thyroiditis. Hum Pathol 19(11): $1315-1326$.

Ito K, Maruchi N (1975) Breast cancer in patients with Hashimoto's thyroiditis. Lancet 2(7945): 1119-1121.

Kumar Vinay (2010) '24: The Endocrine System'. Robbins and Cotran Pathologic Mechanisms of Disease. 8th edn. Elsevier: Philidelphia, PA, pp 1111-1205.

Larson SD, Jackson LN, Riall TS, Uchida T, Thomas RP, Qiu S, Evers BM (2007) Increased incidence of well-differentiated thyroid cancer associated with Hashimoto thyroiditis and the role of the PI3k/Akt pathway. J Am Coll Surg 204(5): 764-775.

Macksood W, Rapport RL, Hodges F (1961) The increasing incidence of Hashimoto's disease. Arch Surg 83: 384-387.

Maruchi N, Annegers JF, Kurland LT (1976) Hashimoto's thyroiditis and breast cancer. Mayo Clin Proc 51(5): 263-265.

Motoi N, Ozawa Y (2005) Malignant T-cell lymphoma of the thyroid gland associated with Hashimoto's thyroiditis. Pathol Int 55(7): 425-430.

Muller I, Pinchera A, Fiore E, Belardi V, Rosellini V, Giustarini E, Giani C (2011) High prevalence of breast cancer in patients with benign thyroid diseases. J Endocrinol Invest 34(5): 349-352.

Nose F, Ichikawa T, Fujiwara M, Okayasu I (2002) Up-regulation of cyclooxygenase-2 expression in lymphocytic thyroiditis and thyroid tumors: significant correlation with inducible nitric oxide synthase. Am J Clin Pathol 117(4): 546-551.

Ott RA, McCall AR, Jarosz H, Armin A, Lawrence AM, Paloyan E (1987) The incidence of thyroid carcinoma in Hashimoto's thyroiditis. Am Surg 53(8): $442-445$.

Pisanu A, Piu S, Cois A, Uccheddu A (2003) Coexisting Hashimoto's thyroiditis with differentiated thyroid cancer and benign thyroid disease: indications for thyroidectomy. Chir Ital 55(3): 365-372.

Repplinger D, Bargren A, Zhang YW, Adler JT, Haymart M, Chen H (2008) Is Hashimoto's thyroiditis a risk factor for papillary thyroid cancer? J Surg Res 150(1): 49-52.

Sano H, Kawahito Y, Wilder RL, Hashiramoto A, Mukai S, Asai K, Kimura S, Kato H, Kondo M, Hla T (1995) Expression of cyclooxygenase-1 and -2 in human colorectal cancer. Cancer Res 55(17): 3785-3789.

Sclafani AP, Valdes M, Cho H (1993) Hashimoto's thyroiditis and carcinoma of the thyroid: optimal management. Laryngoscope 103(8): $845-849$.

Segal K, Ben-Bassat M, Avraham A, Har-El G, Sidi J (1985) Hashimoto's thyroiditis and carcinoma of the thyroid gland. Int Surg 70(3): 205-209.

Yamashita N, Maruchi N, Mori W (1979) Hashimoto's thyroiditis: A possible risk factor for lung cancer among Japanese women. Cancer Lett 7(1): 9-13.

This work is published under the standard license to publish agreement. After 12 months the work will become freely available and the license terms will switch to a Creative Commons AttributionNonCommercial-Share Alike 3.0 Unported License. 